\title{
Seeing Pedagogically, Telling Phenomenologically: Addressing the Profound Complexity of Education
}

\author{
Tone Saevi, NLA University College, Bergen, Norway \\ Email: ts@nla.no \\ Andrew Foran, St. Francis Xavier University, Antigonish, Nova Scotia \\ Email: aforan@stfx.ca
}

\begin{abstract}
The paper exemplifies how we as teachers see children, and indicates ways of understanding the existential educational meanings of what we see. The authors suggest that the phenomenon of seeing is a personal and relational intentional act that opens up, as well as delimits educational practice. A hermeneutic phenomenological approach to education is suggested and the thought of seeing and telling as interwoven representations is put forth. However, despite a phenomenological inquiry's immense qualities as a pre-reflective experiential source to understanding, the authors believe that phenomenology cannot overcome or erase the aporetic unavailability of a pedagogical practice and a pedagogical-ethical language. The paper intends to show that seeing pedagogically always will be more complex, paradoxical and unsettled than what can be shown and told phenomenologically.
\end{abstract}

\section{Introduction}

Hannah Arendt (1958) considers the "capacity for beginning" as the basic quality of the subjective human condition, and relates this capacity first and foremost to reflexive action. Yet, she prefers the poetic narrative literary form as the best means to express human historical memory and experience. Arendt's (2006) fundamental commitment to art, language and poetry, as the intent of and energy for human experience, is both a commitment to the story as the medium that best can witness human experience and action, but also to the poetic form that best reveals who we are not just what we are. Arendt shares the understanding of poetic writing as "the most human art" (as cited in Dayal, 2000, p. 11) with European educators like Klaus Mollenhauer, Otto Friedrich Bollnow, Martinus Langeveld, and such Continental philosophers as Martin Heidegger, Rainer Maria Rilke, Jean-Paul Sartre, Simone Weil, Gabriel Marcel, and Julia Kristeva, some of whom are poets themselves. Kristeva (2000) takes her point of departure in Arendt's philosophical basis in the poetic narrative of "the human capacity for beginning" (p. 6), by suggesting that today's culture is forgetting the sovereignty of the subject in the homogenizing process of globalization. This forgetting of the subject, the person, the human being, the child, as the basis of experience and memory is not only a crisis for culture, but is, for our discussion specifically, an educational crisis. We wish to raise an educational awareness, in the face of this crisis, by asking once again to see the child, and we wish 
to show fundamental pedagogical meanings although always incomplete of the encounters between adult and child. Daily encounters, the quotidian of life, says Gosetti-Frencei (2007), "is built up in daily experience, by everyday habits, by the sedimentation of ordinary expectations of the world" (p. 1). For adults who share their worlds with children by living and experiencing everyday life, they must step outside the habitability of the everyday and the taken-for-granted, in order to disrupt and resist trivialization of their encounters.

Our paper explores the educational meaning of pedagogical encounters between child and adult, student and teacher, as a moral and pedagogical relational practice explored through the lenses of hermeneutic phenomenology. Our intent is to address three experiential examples of the constant subjective being and coming into being of the child or the young person in school settings. We will address some of the unique and heterogeneous forms of myriad existential beginnings, and by telling these distinctive experiences we aim at countering the educational homogenizing process. In other words, the focus is on the educational relation as a way of seeing, encountering, and understanding children and young people, and hermeneutic phenomenology as a manner of exploring, expressing, and showing the unique meanings of education. The concession to dilemma however, is to show in a convincing way that the complexities of the pedagogical encounter nevertheless surpass the sensitive, inventive, and unspecialized language of phenomenological inquiry. Pedagogy, primarily understood as aporetic existential relationality, always is and must be more than what can be seen and told in research.

\section{Seeing and acting}

Our pedagogical point of departure is in the European educational tradition that tends to blur the borders between school and home, professional, and personal connections to children, by "referring to the cultivation of the inner life or human soul of the child or the young person, and to the person's inauguration to culture, tradition, and humanity" (Friesen \& Saevi, 2010, p. 126). The core of the phenomenological and existential European pedagogy is not based on theoretical conceptions, methods and developmental doctrines, but on lived relationality experientially sensed and existentially described and interpreted. The lived and living relational experience of the encounter between adult and child therefore precedes educational methods and procedures that tend to dominate teacher education in the guise of pedagogical intention, and profoundly challenges pedagogical practice and reflection (Saevi, 2011; Foran \& Olson, 2008).

One of the most common acts in the multitude of educational practices is the act of seeing students, teachers, others and oneself. The significance of how we are seen and how we see others is dealt with in philosophy, phenomenology and education by Sartre (1992), Merleau-Ponty (2002), Levinas (1997), Bollnow (1989) and Mollenhauer (1983), to name a few. From a phenomenological context, Paradis (2002) also clearly captures the significance of the pedagogical look within classroom settings. Teachers are trained in the importance of making eye contact and the power and relevance it has for classroom management and even discipline. Paradis questions what the look actually means and how the look is experienced. A most important aspect to the look is the figurative meaning of "a coming together" (para. 6); eye contact is "a shared look [...] that allows two people to touch each other, to 'be' 
together in an intimate way" (para. 7). Paradis reminds us that pedagogy is a special kind of understanding relationship: "The teacher must be willing to see the student as someone who must be inspired, led, guided on the way to becoming a whole person" (para. 20). John Berger with his television series Ways of Seeing (adapted to a book in 1972) challenged our ways of thinking about art and art criticism, and the insights have relevance for educational seeing. Because seeing comes before words, there is a gap between what we see, and what we can tell of the things we see. Berger (1972) claims:

It is seeing which establishes our place in the surrounding world; we explain that world with words, but words can never undo the fact that we are surrounded by it. The relation between what we see and what we know is never settled. (front jacket)

However, like the painter's way of seeing is recognizable in the colors, marks, and strokes on the canvas, the teacher's way of seeing students (as well as the student's way of seeing the teacher, and each of them seeing each other) is reflected in the choice of words and in his or her way of phrasing, focusing and reproducing the actual encounter. Berger shows us that no image is timeless, not the photo, nor the painting, because moments in time and space always include and implement a perspective. What we see is dependent on where we are and when, and this is congruent with our place in time and space. Van den Berg (1977) shows that seeing implies receptivity and intentionality, and that seeing all that one sees is receptively interpreted as some-thing understood. We tend to see what we understand and understand what we see. Seeing thus, does not really take place in the eye, but in what is seen, out there where the meaning of the seen is found, rather than here where the I (eye) is located. The immediate connection between what is seen and the person who sees leads us to Merleau-Ponty's understanding of perception as a pre-reflective experience, which is "the background from which all acts stand out, and is presupposed by them" (2002, p. xi). Perception is not a science, a cognitive act, or a position taken up. Seeing probably is more a question of how one sees and who is seeing than of where and what one sees. The person I am shapes the way I see more than what I see and where seeing takes place. The way I interpret pre-reflectively what I see, might be of more interest than what the object truly is. This means that what is seen is interpreted from how it is understood rather than from what it "really" is. The way persons see is the way the world appears to them. Thus seeing is the background of our acting (see Saevi, 2005).

\section{The unspeakability of existence}

In educational settings usually the teachers and students are doing the seeing as part of the daily routines and educative encounters. In the classroom, they mutually relate to each other and focus on educational activities by studying curriculum subjects, following school policies, and conventions of subject teaching. But there are moments in education when the world itself can move our perceptions by looking back at us. Sovereign existential experiences might impress a look upon us and ask who we are, while we at the same time look back in awe. Experiences of this kind might emerge from nature as well as from culture. Teacher and students, inside or outside the classroom, might be connected experientially for lifetime through such moments (see Foran, 2006). Although each person is present in the moment in his or her personal 
way, and subjectively interprets and expresses the actual experience different from the others, there might be a lived-throughness of the experience, perhaps unspoken and unspeakable, that somehow is shared. The immense complexity of a shared educational moment is embedded in the newness of the moment and in each person's reflexive seeing of the experience; both qualities belonging to the experience as human phenomenon (Gadamer, 1985). In some moments though, the newness of the experience is stronger and more vivid than in others. Some moments reveal "a spontaneous voice speaking from and embedded in existence" (Saevi, 2012a, p. 2). This is what a teacher tells from a particular moment during an excursion with a class of geology students un-expectantly encountering a group of whales.

The boat came to a stop in the middle of pilot whales. They were cresting and blowing just meters from the boat. It was incredible. A few of the whales were just floating and kind of listing to the side, the captain called down to us and said they were logging which means resting. You could see their eyes looking at us. What happened next changed us that day. There was a baby, a calf that was born, according to the captain, during June. This little whale kind of stood up and was looking directly at us. The captain said the calf was spy hopping; they do that when they are curious about something and want a better look. The baby went under only to pop up again closer, and it was looking right at us again. We were all silent and frozen just staring back in stunned amazement...I have spent far too much time studying dead things - rocks, fossils, and land formations. That day we were being studied, and I am curious about what conclusions that little creature realized after seeing us. ${ }^{\mathrm{i}}$

Is this an experience of watching or of being watched? Indeed, what is the experiential difference between seeing and being seen? What is it like to see someone for the first time and to be looked at by someone who sees you for the first time? The teacher, the students and the baby whale share this experience in the moment of seeing each other. Sartre (1992) shows that looking and being looked at in the experiential moment mutually exclude each other. We must in the moment do either. However, unlike the look exchanged between human beings, the looks between a human being and an animal are looks "across a narrow abyss of non-comprehension [...and] ignorance" (Berger, 1980, p. 8). I cannot unmask the secrets of the animal as the animal cannot unmask mine. But we have in common that we both have the sense of seeing, and might look at each other with curious interest. So we might as human beings feel a certain unity with the animal in the moment of looking and being looked at. An animal, however, cannot connect with me in the way another person can. Even if the encounter is hostile, or we do not share the same language, the very fact that language exists, provides the glance between two persons with intentionality. "The abyss between us is bridged with language," Berger says (p. 6). Thus, two persons can confirm each other by their glances. The term confirmäre from Latin, means a strong strengthening, ${ }^{\text {ii }}$ and so a confirming human glance might have the power to strengthen, fortify, and verify the existence of another human being. ${ }^{\text {iii }}$ A glance is at the deepest levels of our existential and personal experience of living in the world alongside others (Saevi, 2005, p. 61). The moment that disrupted the teacher's everyday seeing might have been a realization of being under the gaze of another (human or animal), and the vulnerability this created for those on the boat. There 
existed the possibility of a pedagogical response, to not take for granted what the teacher was seeing, acknowledging the significance of that adult-child bond. And for teachers this surpasses education. Hence, the pre-reflective could be a moment of recognition seeing past the conditions of school, and to see again the humanity of those swept away in a moment of speechless awe that the world presented. Yet, language cannot in any way capture that innocent moment of being studied, and the multitude of sensations, emotions and thoughts raised in these young adventurers.

Still, seeing might have its own language that speaks to us from inside the experience. As Heidegger (2001) claims, the incapability of thinking, "to say that which must remain unspoken," is what "would bring thinking face to face with its matter" (p.11). The complex experiential world that we live in, and which the encounter between human and animal is an example of, literally makes known to us the constraints of phenomenological thinking and writing. In Lingis' text The community of those who have nothing in common (1994) he shows how our habitual understanding of relationality as a homogenous harmony excluding the unknown, is profoundly disturbed by the unspeakability of those on the margins of the world. The utter otherness of the other might sometimes be challenging us in the unattainability of nature or animals. Lingis points to the experience that language sometimes should "be seen as arising out of the murmur of nature - of animals and finally of all things that are and that resound" (p. x). Sometimes what is said is not all that important. The importance is to be there, the thereness of being fully present, and to relate attentively to what is there and what speaks through its very being. Lingis (1994) writes:

What speaks is someone in his or her materiality as an earthling; one that breathes sighs, and vocalizes in the rumble of the city and the murmurs of nature; one whose blood is warm with the warmth of the sun and the ardors of the night. One whose flesh is made of earth dust that shall return to dust - who stands facing another with the support of the earth rising up in him or her; one whose face is made of light and shadow and whose eyes are made of light and tears. (p. 117)

Lingis lifts out existential moments, or what he entitles "the murmur of the world" (p. 70), by others called the il y $a$ or the there is, and understands the moments as "the beginning of communication" (p. 114). Limit-situations, situations of existential potentiality, are numerous in human life, although we might as teachers (and students) not always be aware of them. Sometimes in education, like in situations in daily life, we depend on the mere givenness of existence in order to start anew, to begin communication, or to see our capacity of beginning as such. And although we, in situations where existence outwits us, are left to pass on unconditionally what has been given to us, words fall short of the experiential richness and unavailability of that which after all was given to us in the experience. And like the class above, we become stunned in a moment of being touched by existence.

\section{Seen but still not seen-or something that is seen but cannot be told}

Seeing is reciprocal in the way that we see and are seen by others, be it another human being or a living creature from the depths of the ocean. The glance might be new, like from a newborn, or old like from an acquainted teacher. Seeing though, in the actual encounter; what I saw and the reflection that portrays my seeing, always precedes 
words and establishes a gap between what is seen and what can be told. We are not always fully aware of either seeing or being seen, or of the consequences attained in that act. This is especially so if the glance of the other, which often is the case, is unclear and ambiguous. But seeing could be even less than vague and confusing. Seeing could in fact be unseeingly or blind (see Saevi, 2005, p. 169). Although lacking mindfulness, or being unseeingly or blinded, seeing something is part of being in the world. Seeing, like being, is unaware of itself in the moment of seeing, and thus must be post-experientially reflected on to be consciously addressed. However, both reflective and inattentive seeing, according to Merleau-Ponty (1997), share a commonality - they both lack precise examination and expression. He says: "The world is what I perceive, but as soon as we examine and express its absolute proximity, it also becomes inexplicably, irremediably distance" (p. 8). The meaningfulness of the moment is not fully expressible in words. The image, what I see, precedes thought and words. An image or a reflection created from a moment of seeing might move us before we know what it is actually about. Bachelard (1994) notes that an instant image somehow might have "touched the depths before it stirs the surface" (p. xix). The reflection of the image or the meaning of the story might create a "connotative iconic presentation in us before we understand the meaning of it intellectually" (Saevi, 2005, p. 173). This in fact is the human condition of being before thinking, or ontology before epistemology. One might as teachers ask how we encounter the child relationally in a situation where his or her "inaccessible being" somehow is in question. Terje, now a grown man and himself a teacher, shares a significant experience from his school days:

I was eight or nine, and daily bullied in the schoolyard, especially by a strong boy a year older than me. I never fought back. My teacher saw some of the incidents and made an effort to stop the bullying by rebuking the older boy and encouraging me to fight back next time. But deep within me I had a specific motive for not fighting back. I never told him what I repeatedly told myself; I was convinced that as Jesus had never defended himself, neither should I. ${ }^{\text {iv }}$

The teacher intends to stop the incidents of bullying and he does so in a way that is reasonably common amongst teachers. He talks to the offender, and comforts and encourages the victim to defend himself. But the victim does not seem to take his teacher's advice. To help cope with the complex situation, the child does what children sometimes do, he compares himself to a person who was worse off than himself. His sense of the situation differs from the teacher's former knowledge of students, and does not fit with the common principle of rebuke. But this is clearly how Terje expressed his experience.

In a corresponding way to Terje, the young key figure Ingemar in the Swedish movie, My Life as a Dog (Bergendahl, 1985), also responds differently to his experienced life-situation than what adults expected. Over and over again he reminds himself of how it might have been for Laika, the Russian space-dog, to move towards a slow annihilation inside the space capsule circulating around the earth. None of the adults around him are able or willing to see with understanding how he actually faces the despair and confusion he experiences in the various situations of his mother's illness and death. Like in Terje's situation Ingemar's experiential motives are epistemologically concealed and unspeakable. The connection between what the adults see and what they understand thus is never settled. What they see is affected by 
what they know, or believe that they know, rather than what is actually there to be seen and meaningfully reflected, although not in anticipated conventional ways.

These experiences might not just be occasional pedagogical episodes; these two young boys might not necessarily be extraordinary. In a sense, one could say that all children are extraordinary, and all pedagogical experiences are in a profound sense inexpressible. Thus what the adults see and what they really know of a pedagogical situation is not readily available and settled. The experiences of Terje and Ingemar may serve as examples of the profound unavailability of every child and of the ambiguous and unfixed quality of educational moments. The question is how teachers and adults possibly could see in order to see what might still be seeable in situations that are only partly open to current educational language and rationality. Or rather, how do we see and speak in order to pedagogically address the child and his or her lifeworld without knowing or seeing everything? How might pedagogical ways of seeing allow for the child's invisible (and unutterable or unreachable) being to be addressed, although always unsettled and incomplete? And perhaps more profound, should we in fact pedagogically aim at seeing and understanding everything?

Wittgenstein (1999) suggests that the "subject does not belong to the world, but is rather a border to the world" (sentence 5.632). If Wittgenstein is right, how might we as teachers and adults see, sense and speak so that we might address the subjective child, and practice a "border-line education"? Pedagogical acts perform at the border between the self of the adult, the demands of society and the self of the child. The uniqueness of the child might be understood as a "residue of self" that does not enter into the existing orders and explanations, and as a result, somehow "resists" the inculcation to socialization. Although it might be hard for us to think of ourselves as lonely subjects, as someone who, in a certain sense, is completely solitary in spite of profound relational orientation, this might be the case in some situations in life. Even when surrounded by and attended to by persons and structures, Terje and Ingemar were still in a sense solitary in their counter-response to the claims of socialization and when encountering the anticipated assimilation of pedagogical conventions. However, even if through sight, touch, sympathy, and cooperative work we are with others in social situations, our transitive relationships never exist in a singular way. I still never am the other person (Levinas, 2002). Levinas furthers this by saying: "One can exchange everything between beings except existing. In this sense, to be is to be isolated by existence," (p. 42). Human experience in general and pedagogical experience in particular show that Levinas is poignant in this reflection on humaneness.

What Terje and Ingemar actually are involved in is the tough labour of existing. They work on their drafts of subjectivity by acting and reflecting meaningfully on their unique positions in life. The good guiding adults are present and see, but their reflection and words fall short of interpreting these situations to possibly make a pedagogical difference. The two boys take responsibility for themselves by being occupied with questions of how and why they exist in particular moments of daily life. The moments experientially seem to be only partly understandable to adults, who are prevented by conventions, their grown-upness and lack of reflective language, to somehow address their seeing in terms of what was actually seen. These pedagogical situations, and thus the potential relations included, are in fact immensely complex and paradoxical. When children essentially shape their self, their existential process usually seems to go unrecognized by adults. Levinas (2002) verifies the solitary 
quality of the subjective relationship to self by saying: "identity is not an inoffensive relationship with itself, but enchainment to itself; it is the necessity of being occupied with itself' ( $p$. 55). The subjectively experienced moments where the child in a multitude of ways, invisible to others, addresses his or her self, are subtle connections to self-active subjectivity and existence (Mollenhauer 1983). The adult might be part of the situation with the child, but still "the meaning of the event for the child with regard to significant aspects seems to be unattainable for the adult" (Saevi \& Husevag, 2009, p. 39). One might as adults respectfully admit, that most of the time children live backstage, and are seen, but not reflectively noticed. Bachelard (1994) suggests that "man is a half-open being," (p. 222), and in our experience this is particularly true for children and young people.

\section{Something that looks like nothing}

According to Heidegger (1962), humans are inherently ontological. We do not necessarily reflectively understand all that we are doing, but in our manner of being, there is always an implicit sensed understanding. This pre-reflective understanding, Heidegger calls "pre-ontological" (p. 32). The pre-ontological understanding of how one is situated in the world, or where one finds oneself, always comports with existence and how this particular way of existence is for me. In Heidegger's words: [Dasein's] "essence lies rather in the fact that in each case it has its Being to be, and has it as its own" (p. 33). Thus the human lived experience always has its own moody quality, and although the sense may be pre-cognitive and ever so vaguely felt it "always has some mood" (p. 173). Heidegger continues: "The pallid, evenly balanced lack of mood (Ungestimmtheit), which is often persistent and which is not to be mistaken for a bad mood, is far from nothing at all" (p. 173). According to Heidegger, one might experience, that what looks like "nothing" still might be "something". In the following common classroom situation where a student asks for permission to go to the washroom, what might look like "nothing" may well be a kind of innate sense of "something" to Niklas, a 16 year old student with learning disability.

The signs are unmistakable. Since the class started he repeatedly has changed his position in the chair, uncomfortably crossing his legs. Finally, he raises his hand: "May I go to the washroom, please?" The teacher that apparently expected his request sighs audibly. Niklas needs guidance to the faraway men's washroom and he needs assistance among same age adolescents. But obviously he is not able to wait for the break when she can assist him. The teacher responds somewhat dismissively: "In the case that you need to go to the washroom immediately you'll have to use the small washroom just outside in the hallway." The class giggles. The nearby washroom is the girls' washroom. To Niklas however, boy or girl makes no difference. He does not seem to understand exactly why they laugh, but his expression is bewildered when he leaves the classroom.

To Niklas, the difference between the boy's and the girl's washroom seems to be a cognitively pointless distinction. One might think then that because the event seems to make no comprehensive difference to him, the teacher's answer might appear appropriate and adapted to the present situation. But what is this "something" that he apparently seems to sense as he leaves behind the classroom with his laughing 
classmates? One might wonder if the situation may have still opened in Niklas a particular state of sensation, although he does not seem to understand the situation in the same way as his giggling classmates. However, what might be his experience of the situation?

Heidegger (1962) might help us address the situation as he suggests that "man's 'substance' is not spirit as a synthesis of soul and body; [but] it is rather existence" (p. 153). Could it be that Niklas' experience was existential rather than intellectual or emotional? And furthermore, could it be that his experience of existence is a participatory existence, a being with the others, a partaking in the situation, still, in a personal way? Bachelard (1994) emphasizes that "the essence of life is not 'a feeling of being, of existence,' but a feeling of participation in a flowing onward, necessarily expressed in terms of time, and secondarily in terms of space" (p. xii). How then might time be experienced to Niklas in the very moment of the event? How do we experience time in situations where everybody but us, seems to understand the situation? Do we not tend to feel that the moment lasts forever, or perhaps collapses to a crawl? The very moment of sensed incomprehension somehow seems to adhere itself to us. The moment comes back again and again to our feeling of self, and somehow in this process our body fails to continue its free movements, as its incomprehensible experiential appendage seems to prevent it. We spin around the unclear experience of being put aside, although our momentary experience is not a reflective pondering on what it was that we did not catch in the moment. Rather, there is a sense of being thrown into a void of loneliness (van den Berg, 1972). For a moment, Niklas seems to be prevented, barred even, from sharing the everydayness of life in his class.

Although his experience somehow separates his existence from that of the others, the question at stake is if and in what ways pedagogical care might address the unique child's subjective experience. Did or did not the teacher's answer make a difference to Niklas' experience of self in the situation? Did he somehow sense that being a boy in the girls' washroom would be inappropriate, although he might not have understood the fuller meaning of the situation in the same way as his classmates did? Did it, in one way or another, make a difference to him not being recognized as a boy, or not to be addressed as a boy that in this situation was able to understand the distinction in the same way as the others? It seems like his possible experience of self in the situation was unrecognized and devalued, and we might fear that forgetfulness in the flux of time prevented the teacher from acknowledging Niklas' self at all. We suggest that moments of non-recognition likely pedagogically mean more to students than we as teachers might possibly believe. Van Manen (2002) elucidates the meaning of recognition in the following way,

To receive recognition literally means to be known. Someone who recognizes me thereby acknowledges my existence. [...] Recognition is inextricably intertwined with selfhood and personal identity. And self-identity is the realization of the tension between the being of self and the becoming of self, between who we are and who and what we might become. (p. 38)

The significance of a teacher's recognition, in fact is nothing less than the question of addressing the self of the student. Addressing the self of the student is something else than challenging his or her cognitive capacity of understanding (Foran, 2006). To 
address the student's self somehow is to see his or her personal existence in the present, and in this particular presence, open up the possibility of a future. How the student experiences him- or herself as "seen" in the moment, might have a ripple effect toward his or her coming of self. Somehow, present encounters might alter the emerging self of a person. How Niklas senses that his self was recognized while leaving the classroom on this particular day is not "nothing." Rather it is something quite significant. Besides, being significant for who he is and is to become in the time to come, the experience means something for who "he is coming to be" (van Manen, 1991, p. 33). Could it not also be that sometime in the future Niklas might come to understand the meaning of this situation, and sense what was at stake for him? Niklas will mature, learn, become more aware, and he might understand subtle things or concealed messages in language that he did not understand that particular day. The moment might even, sometime in the future, flash back on him. However, the pedagogical question is if we as teachers should or should not care pedagogically for the possible future self of the students, as well as that of their present self. And if Niklas were not to come to know the difference between girls and boys in the future, would we then understand the teacher's practice as pedagogically appropriate and caring? Would the relation between how the teacher saw the students' situation and her words to address the actual moment, embracing the ontology and the epistemology of the situation, then become a pedagogical response, or not? Or would a pedagogical address have to move beyond even an ontological concern in order to be pedagogical?

\section{The impossibility of telling what you see}

The three examples above hold deep educational, pedagogical and phenomenological meanings that only partly and insufficiently can be brought to light, by exploring their existential whatness through the subjective experiential meaning they have to the persons involved. Because every way of being in the world is a way of knowing the world, we can only know the world from our personal perspective. This realization brings forth some important questions. How might a teacher possibly know students and understand their experiences? And moreover, how might we understand human conditions and experiences that are even "more" different? To what extent might we pedagogically understand, and how do we pedagogically address and formulate our understanding of particular moments? The more different the experience and perspectives are, the more difficult it might be for teachers to see pedagogically and to understand young people caringly, and to acknowledge that they do not and cannot see and understand everything.

Being a human being, child or adult, student or teacher, is a way of knowing the world from the particular personal perspective of this person. In spite of the inaccessibility of the personal experience a teacher constantly has to strive to encounter every student personally in ways that address their self-understanding and intend to support their subjective being. The way teachers encounter the students pedagogically, is related to the way they see and experience episodes with them. And the reverse is true as well; the way teachers see students is vital to how they experience and understand themselves in pedagogical encounters. Seeing as a sensing-feeling-understanding act includes all senses, and thus incorporates the full sensuous engagement in teaching and being with students (Foran, 2005, 2006, 2008; Levin, 1988; Saevi, 2005). Levin (1988, p. 60) quotes Heidegger in order to 
emphasize the existential and amalgamative quality of the human senses: "Seeing is [primordially] determined, not by the eye, but by the lighting of Being. Presence within the lighting articulates all the human senses." In the examples above, the students as well as the teachers, disclose something significant about their Being, in the encounter with each other. They show who they are through their speaking and acting. Their words, perspectives, angles and positions, are according to Arendt (1958) representing their subjective being, from which we all always speak and act. Therefore what is seen when we see others, as well as ourselves, creates recognizable traces of identity and self in the most profound way.

Seeing someone or something, however, is not synonymous with reflective knowing. The lived experience of seeing a student in the pedagogical encounter is not the same as having knowledge about students, pedagogy, or teaching. Even though most teachers do have a great deal of professional and personal knowledge in regards to students, subjects, and pedagogical practice, cognitive and professional knowledge are secondary to the experience of actually seeing students as a way of relating and existing. Seeing and being seen, in the pedagogical encounter are experiential phenomena that help us understand the meaning of the special relationship between teacher and student. A teacher's seeing, is an immediate, sensed and embodied lived experience that is prior to reflective knowledge. While knowing students is a cognitive and conscious area of the teacher's professional practice, experiencing the students, is related to sensing and understanding them in a more profound and prereflective way. Thus seeing is not first noticing that there is a person to see, and then deciding to see him or her for who they are. In fact, the opposite is true; the sensing eye (I) discovers the person and then we become consciously aware of the fact that we are seeing him or her. Seeing is instantly and intuitively sensing the other person or thing in our surroundings. Seeing is a response to the world, which is always already there to be seen-in fact waiting to be seen. I know the world as a place where my sensuous engagement aims at discovering people and objects within it. My seeing quite often is a mere givenness of a generous world, more than a planned sensing and acting upon the world. One might say that I see the world through my realization of self, and as such, I am constantly, although always insufficiently, interpreting the world through my senses. This is so because the world is always much more than I can overcome and keep together, even with my perception. Seeing is a way of knowing the world, yet not primarily in terms of cognitive information, but rather as an embodied and sensed knowledge that generously ties me to the world. Thus the experience of seeing, and being seen, are ontological experiences rather than epistemological terms.

The experiential leap between seeing and telling, and between the experience and the symbolic representation of the experience, is an insoluble problem in research, and even more so in phenomenology. This methodological aporia seems to be doubled when phenomenology encounters education. Lippitz (2007) sees the aporia of the connection between the experience of the other and the expression of the other like this:

When the other or foreign becomes knowledge, it is always presupposed that the otherness or foreignness is not fundamentally different in comparison to the consciousness which experiences and reflexively appropriates it. It ceases to be something that is known even its foreignness, and becomes a part of reflexive consciousness. 
The initial difference between the self and the other, the starting point of the self and the knowledge of the other, is effectively erased. It disappears in the sameness of reflection. (p. 84)

Saevi and Husevag (2009) point to the importance of the potential encounter of the lifeworlds of adults and children, for the adult to possibly elude situations where they "see the child in the continuity of what it has been so far, without the potential of something new" (p. 39). The aporetic character of the pedagogical relation, as well as the experiential complexity of inter-human co-existence, precede reflective planning and acting, and place us in a constant challenge as teachers. We cannot as teachers "detach" ourselves from conventional educational practices, or overcome our educational focus on synchronization of the students' view and wills. We cannot disengage from absorbing the child's original human difference in the "sameness of reflection", as Lippitz writes above. In fact, "our challenge as adults and pedagogues is to become more attentive to the experience of the child and to acknowledge the child's utter otherness as the basic precondition for pedagogical relational practice" (Saevi \& Husevag, 2009, p. 40).

As phenomenologists, "speaking" a phenomenological "language," we might in fact be able to "say" what other "languages of education" cannot "talk of", in ways that might illuminate and edify educational theory and practice. The existential, phenomenological language sometimes may be able to speak of that which does not fit; the ambiguous, the incompatible, the seemingly insignificant, and that which looks like "nothing." In spite of rational ruptures, discontinuity, and disturbances some of these elusive human experiential qualities can be spoken of in ways that might add meaning to life, and be experienced as trustworthy and educationally relevant to students and teachers (Saevi, in press). The crucial point, however, is that regardless of the cleverness of the phenomenologist and the rigor of the phenomenological method, even a phenomenological approach cannot outwit the meaning of pedagogy and the complexity of its practices. Phenomenology aims at opening up and exploring a human lived experience and phenomenological telling thus is a way of relating to the "speaking" of the phenomenon. The word tell from German zählen, with the root talo, in fact means to narrate or relate ${ }^{v i}$. Although phenomenology and pedagogy share the existential interest in seeing and telling of human existence and coexistence, and such, the two seem to complement each other, pedagogy is concerned with the child, the new generation, without whom there would be no need of a seeing or a telling. Phenomenology as method and philosophy, might do what others cannot do, and elucidate what other methods cannot see. Language, though, spoken and written, nevertheless falls short of life's own inherent complexity and unspeakability. Pedagogy as a way of living caringly and responsibly with children and young people can be told and showed phenomenologically, and thus in fundamental ways address our sensibility for the good and right. But basically education, as a way of living pedagogically with children and young people, is the impossible possibility that cannot really be adequately and rightfully told of because of its complexity and inherent aporetic qualities. Or as Franz Kafka (2002) confesses in his letter to his father "the magnitude of the matter far exceeds the scope of my memory and rationality" (p. 5). ${ }^{\text {vii }}$ 


\footnotetext{
${ }^{\mathrm{i}}$ The description is taken from a collection of interviews with teachers in Canada from 2006 that are described in Foran (2006, p.222-223).

ii www.etymonline.com

iii Il y $a$ is the common French expression meaning there is or there are. Emmanuel Levinas uses the term to indicate the "speaking behind the wall", in a similar way to Lingis" term "the murmur of the world".

iv The description is taken from a collection of interviews from 2001-2002 with former and previous students in Norway that are described, translated, and referenced in Saevi (2005).

${ }^{v}$ The description is taken from a collection of interviews from 2001-2002 with former and previous students in Norway that are described, translated, and referenced in Saevi (2005).

${ }^{\mathrm{vi}}$ www.etymonline.com

vii Original text in German: «Weil die Grösse des Stoffs über mein Gedächnis und meinen Verstand weit hinausgeht" (Mollenhauer 1983, p. 9).
}

\section{References}

Arendt, H. (1958). The human condition. New York: Doubleday \& Company Inc.

Arendt, H. (2006). Between past and future. New York: Penguin Books. (Original work published 1954).

Bachelard, G. (1994). The poetics of space. Boston: Beacon Press. (Original work published 1954 in French).

Bergendahl, W. (producer), \& Hallström, L. (Director). (1985). My Life as a Dog [Mitt liv som hund] [Motion picture]. Sweden: FilmTeknik \& Svensk Filmindustri.

Berger, J. (1972). Ways of seeing. London: British Broadcasting Corporation and Penguin Books.

Berger, J. (1980). About looking. New York: Pantheon Books.

Bollnow, O.F. (1989). The pedagogical atmosphere. Phenomenology + Pedagogy, 7, pp. 5-63.

Dayal, S. (2000). Introduction. In J. Kristeva, Crisis of the European Subject (pp. 146). New York: Other Press.

Foran, A. (2005). The experience of pedagogical intensity in outdoor education. Journal of Experiential Education, 28(2), 147-163.

Foran, A. (2006). Teaching outside the school: A phenomenological inquiry (Unpublished doctoral dissertation). The University of Alberta, Edmonton,

Foran, A. (2008). An outside place for social studies. Canadian Social Studies, 41(1). Retrieved from http://www2.education.ualberta.ca/css/Css_41_1/ARForan_ outside_place_SS.htm

Foran, A., \& Olson, M. (2008). Seeking pedagogical places. Phenomenology \& Practice, Volume 2 (2008), No. 1, pp. $24-48$. 
Friesen, N. \& Saevi, T. (2010). Reviving forgotten connections in North-American teacher education. Mollenhauer and the pedagogical relation. Journal of Curriculum Studies, 42(1), pp. 123-147.

Gadamer, H.-G. (1985). Truth and method. New York: Crossroad. (Original work published 1960 in German).

Gosetti-Frencei, J.A. (2007). The ecstatic quotidian. Phenomenological sightings in modern art and literature. Pennsylvania: Pennsylvania State University Press.

Heidegger, M. (1962). Being and time. San Francisco: Harper \& Row. (Original work published 1926 in German).

Heidegger, M. (2001). Poetry, language, thought. New York: Harper \& Row.

Kafka, F. (2002). Brevet til faren. Oslo: Cappelens klassikere. (Original work published 1953 in German).

Kristeva, J. (2000). Crisis of the European subject. New York: Other Press.

Levin, D. M. (1988). The opening of vision. Nihilism and the postmodern situation. New York: Routledge.

Levinas, E. (1997). Totality and infinity. Pittsburgh: Duquesne University Press.

Levinas, E. (2002). Time and the Other. Pittsburgh: Duquesne University Press. (Original work published 1981 in French).

Lingis, A. (1994). The community of those who have nothing in common. Bloomington Indianapolis: Indiana University Press.

Lippitz, W. (2007). Foreignness and otherness in pedagogical contexts. Phenomenology \& Practice, 1(1), pp. 76-96.

Merleau-Ponty, M. (1997). The visible and the invisible. Evanston: Northwestern University Press. (Original work published 1948 in French).

Merleau-Ponty, M. (2002). Phenomenology of perception. London: Routledge \& Kegan Paul. (Original work published 1945 in French).

Mollenhauer, K. (1983). Vergessene Zusammenhänge. Über Kultur und Erziehung. München: Juventa.

Paradis, P. (2002). The pedagogical significance of the look. Retrieved from http://www.phenomenologyonline.com/articles/paradis.html

Saevi, T. \& Husevag, H. (2009). The child seen as the same or the other? The significance of the social convention to the pedagogical relation. Paideusis, 18(2), pp. 29-41. 
Saevi, T. (2005). Seeing disability pedagogically. The lived experience of disability in the pedagogical encounter Bergen; University of Bergen, Norway, Doctoral dissertation.

Saevi, T. (2011). Lived relationality as fulcrum for pedagogical-ethical practice. Studies in Philosophy and Education, 30, pp. 455-461.

Saevi, T. (2012). Editorial. Phenomenology \& Practice, 6(1), pp. 1-4.

Saevi, T. (in press). Eksistensiell refleksjon og moralsk nøling: Pedagogikk som relasjon, fortolkning og språk. Norsk Pedagogisk Tidsskrift.

Sartre, J.P. (1992). Being and nothingness. New York: Philosophical Library. (Original work published 1943 in French).

van den Berg, J. H. (1972). A different existence: Principles of phenomenological psychopathology. Pittsburgh, Pennsylvania: Duquesne Press.

van den Berg, J. H. (1977). Zien, begrijpen en verklaren van de visuele waareming. Nijkerk: Uitgeverij G.F. Callenbah B.V.

van Manen, M. (1991). The tact of teaching: The meaning of pedagogical thoughtfulness. London, Ontario: The Althouse Press.

van Manen, M. (2002). The tone of teaching. London, Ontario: The Althouse Press.

Wittgenstein, L. (1999). Tractatus logico-philosophicus. Oslo: Gyldendal. (Original work published 1922 in German). 